\title{
A MANIFESTAÇÃO DE EMOÇÕES EM JOGOS INFORMAIS E FORMAIS DE VOLEIBOL NO CONTEXTO ESCOLAR
}

\author{
Raquel Valente de Oliveira' \\ João Francisco Magno Ribas² \\ Luciane Sanchotene Etchepare Daronco ${ }^{3}$
}

\section{RESUMO}

As emoções são manifestadas diferentemente de acordo com as características de jogos e esportes, sendo classificadas em positivas, negativas e ambíguas. Nesse sentido, a Praxiologia Motriz apresenta instrumentos de análise que permitem aprofundar a lógica interna dessas práticas motrizes, considerando também sua lógica externa. Assim, essa pesquisa objetivou caracterizar as emoções manifestadas pelos alunos do CTISM em jogos Informais e Formais de Voleibol. Para isso, como instrumento de pesquisa, aplicamos questionários aos 32 alunos participantes, considerando seus aspectos quantitativos e qualitativos. Os resultados mostraram que as emoções positivas obtiveram a maior frequência de manifestação nos jogos Informais, enquanto que nos jogos Formais foram as emoções negativas. Quando considerado o resultado da partida, as emoções positivas predominaram em alunos vencedores dos jogos Formais e as negativas em alunos perdedores. Portanto, constatamos que o Voleibol propicia a manifestação de diferentes emoções, dependendo do caráter do jogo e do resultado da partida.

Palavras-chave: Emoções. Praxiologia Motriz. Voleibol. Informal. Formal.

1 Graduanda em Educação Física. Universidade Federal de Santa Maria (UFSM). Santa Maria/ Rio Grande do Sul, Brasil. E-mail: raquelvvallente@hotmail.com

2 Pós-Doutor em Educação. Professor da Universidade Federal de Santa Maria (UFSM). Santa Maria/ Rio Grande do Sul, Brasil. E-mail: ribasjfm@hotmail.com

3 Doutora em Ciência do Movimento Humano. Professora da Universidade Federal de Santa Maria (UFSM). Santa Maria/ Rio Grande do Sul, Brasil. E-mail: lusanchotene@ufsm.br

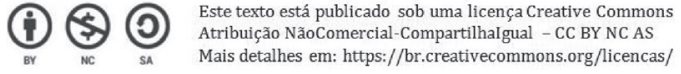




\title{
THE MANIFESTATION OF EMOTIONS IN INFORMAL AND FORMAL GAMES OF VOLLEYBALL AT SCHOOL CONTEXT
}

\begin{abstract}
The emotions are manifested differently according with characteristics of games and sports, being classified in positives, negatives and ambiguous. In this sense, the Motor Praxiology presents analytical instruments for deepening internal logic of these motor practices, considering its external logic also. Therefore, this research aimed to characterize manifested emotions by students of CTISM in Informal and Formal games of Volleyball. Thereunto, as research instrument, we apply questionnaires to 32 participating students, considering its quantitative and qualitative aspects. Results shows that positive emotions had higher frequency in informal games, while in formal games were negative emotions. When considering the outcomes of match, the positive emotions predominated in winner students of formal games, and the negatives in loser students. Therefore, we found that Volleyball provides manifestation of different emotions, depending on of game characteristics and outcome of match.
\end{abstract}

Keywords: Emotions. Motor Praxiology. Volleyball. Informal. Formal.

\section{LA MANIFESTACIÓN DE EMOCIONES EN JUEGOS INFORMALES Y FORMALES DE VOLEIBOL EN EL CONTEXTO ESCOLAR}

\section{RESUMEN}

Las emociones son manifestadas diferentemente de acuerdo con las características de juegos y deportes, las cuales son clasificadas en positivas, negativas y ambiguas. En este sentido, la Praxiología Motriz constituye instrumentos de análisis que permiten profundizar en la lógica interna de las prácticas motrices, considerando también su lógica externa. Así que, esta investigación ha objetivado caracterizar las emociones manifestadas por alumnos del CTISM en juegos Informales y Formales de Voleibol. Para tanto, como instrumento de investigación hemos utilizamos cuestionarios a los 32 alumnos participantes, considerando sus aspectos cuantitativos y cualitativos. Los resultados indican que las emociones positivas obtuvieron la mayor frecuencia de manifestaciones en los juegos Informales, al momento que en juegos Formales fueron las emociones negativas. Al considerar el resultado del partido, las emociones positivas han predominado en alumnos ganadores de juegos Formales y las negativas en los perdedores. Por consiguiente, hemos constatado que el Voleibol proporciona la manifestación de diferentes emociones, dependiendo del carácter del juego y del resultado del partido.

Palabras clave: Emociones. Praxiología Motriz. Voleibol. Informal. Formal. 


\section{INTRODUÇÃO}

Desde que nascemos manifestamos diversas emoções ao longo da vida. Essas manifestações emocionais são suscitadas por acontecimentos, fases da vida ou por resposta a algum fato. Neste sentido, as emoções constituem a primeira resposta às interações com o mundo e com as demais relações afetivas (LAGARDERA, 1999). Assim, cada pessoa possui uma maneira única de repercutir e responder emocionalmente a esses acontecimentos.

Para Bisquerra (2003), a emoção define-se como um estado do organismo caracterizado pela excitação ou perturbação, gerada a partir de um acontecimento externo ou interno. As emoções condicionam o modo como as pessoas vivem em seu cotidiano nas mais diferentes situações diárias, no qual segundo Goleman (1996), as mesmas referem-se a sentimentos, pensamentos, estados psicológicos e biológicos de uma pessoa. Além disso, a maioria das emoções são geradas inconscientemente, desencadeando nos sujeitos distintos modos de agir frente às situações impostas pela sociedade, sendo fatores fundamentais que influenciam em suas relações sociais.

Dessa maneira, Bisquerra (2000) classifica as emoções em três categorias: positivas (alegria, humor, amor e felicidade), negativas (medo, ansiedade, ira, tristeza, desprezo e vergonha) e ambíguas (surpresa, esperança e compaixão). Ainda segundo Bisquerra (2000), a emoção será positiva quando as expectativas de uma pessoa se satisfaçam diante de alguma situação, ou seja, quando seu objetivo é alcançado e os resultados são favoráveis, Ihe trazendo sensações agradáveis e bem-estar. Negativa, se seus objetivos não forem atingidos, proporcionando sensações desagradáveis e desprazerosas, podendo causar frustrações e conflitos. Por fim, a emoção será ambígua se apresentar um caráter positivo ou negativo dependendo das circunstâncias.

No que diz respeito às emoções manifestadas nas distintas situações motrizes ${ }^{4}$, elas são suscitadas diferentemente em cada condição de jogo atribuída aos alunos, fazendo com que os mesmos apresentem inúmeras maneiras de agir emocionalmente frente a cada uma dessas situações. Corroborando com essa ideia, Lavega, Aráujo e Jaqueira (2013), em sua pesquisa acerca das competências motrizes e emocionais, concluíram que a intensidade emocional manifestada pelas três categorias de emoções (positivas, negativas e ambíguas) tem relação direta com a prática motriz realizada e com suas situações motrizes de jogo.

Tendo esse pressuposto, toda prática motriz (esporte, jogo, luta, dança ou ginástica) estimula a excitação de diferentes e específicas emoções em seus alunos, dependendo de suas características e de sua lógica interna ${ }^{5}$. Dessa forma, a prática motriz é uma variável

4 O presente trabalho contou com apoio financeiro do Programa Institucional de Bolsas de Iniciação Científica (PROBIC) da FAPERGS/UFSM.

Para Parlebas (2001, p. 423) a situação motriz é o "conjunto de elementos objetivos e subjetivos que caracterizam a ação motriz de uma ou mais pessoas que, em um meio físico determinado, realizam uma tarefa motriz". São situações de jogo, no qual os participantes se relacionam com o entorno físico e com os demais jogadores inseridos na prática motriz.

5 A lógica interna caracteriza-se como o modo no qual estão preestabelecidas as ações motrizes de todos os jogos e esportes (LAGARDERA; LAVEGA, 2003), sendo o sistema das características das diferentes situações motrizes. Assim, a lógica interna é a chave do jogo, tornando-se possível através dela conhecer as interações estabelecidas entre os jogadores e as ações motrizes derivadas do sistema praxiológico e de suas regras. 
de grande importância e significado para a vivência emocional experimentada pelo aluno no contexto escolar, devendo ser trabalhada pedagogicamente de forma a considerar as características emocionais de seus praticantes.

A Educação Física, por ser uma disciplina escolar que trata do ensino da cultura corporal de movimento de diferentes situações motrizes, suscita relações sociais em que os alunos mantêm interações com os demais. Além disso, a Educação Física é uma área de ensino que almeja alcançar seus objetivos e suas competências educativas por meio de situações motrizes (LAVEGA et al., 2014), possibilitando o acesso ao patrimônio cultural produzido pelo homem relativo aos jogos e esportes ${ }^{6}$.

Como um dos conteúdos da Educação Física escolar, o Voleibol apresenta-se como um esporte dinâmico e singular dentre os demais, devido a não individualização dos ralis na disputa dos pontos, o que impossibilita a execução de sucessivos toques na bola (ação individualizada), e em razão da habilidade motora básica de rebater como forma de atuar durante o jogo (FAGUNDES; OLIVEIRA; RIBAS, 2015). Como uma das principais características do Voleibol e de sua lógica interna, os participantes deverão estar empenhados em alcançar determinado objetivo do jogo, cooperando com seus companheiros e concomitantemente contrapondo-se as ações de seus oponentes para colocar a bola no solo da quadra adversária.

No que diz respeito às interações estabelecidas entre companheiros e adversários, a Praxiologia Motriz, também conhecida como Teoria da Ação Motriz ${ }^{7}$, criada pelo professor Pierre Parlebas, objetiva, dentre outros aspectos, desvelar a lógica interna das práticas motrizes, sendo elas esportivas ou lúdicas. Podemos em outras palavras definir a Praxiologia Motriz como a ciência da ação motriz, ou seja, constitui um instrumento de análise da lógica interna de funcionamento que estruturam jogos e esportes (PARLEBAS, 2001). Partindo desse pressuposto, toda prática motriz pode ser compreendida por meio das interações com os demais jogadores, com o espaço, com o tempo e com o material (LAVEGA, 2010), sendo que estes configuram os quatro pilares básicos da lógica interna.

A partir do conceito de lógica interna, Parlebas elaborou o Sistema de Classificação de jogos e esportes conforme a presença ou a ausência de companheiros e/ou adversários e a relação com o entorno físico. Conforme essa classificação e de acordo com os conhecimentos praxiológicos, o Voleibol configura-se como uma prática sociomotriz de cooperação e oposição pelo fato dos jogadores manter interações de comunicação entre companheiros de equipe e de contracomunicação entre adversários. Assim sendo, Duran

6 O esporte configura-se como o grupo de situações motrizes competitivas e internacionalmente institucionalizadas. Outra importante característica é o forte vínculo do esporte com o sistema capitalista, no qual o sistema se utiliza de conceitos centrais deste grupo de manifestações para colocar acento nas bases dessa proposta, no caso, o individualismo, a competição a qualquer preço e a seleção dos melhores (PARLEBAS, 2001). Essa questão já vem sendo amplamente debatida por autores brasileiros como Valter Bracht, Elenor Kunz, Marco Paulo Stigger, Savio de Assis, entre outros.

7 Para Lagardera e Lavega (2003), a ação motriz constitui a unidade básica de análise e significado elementar da Praxiologia Motriz, na qual representa as propriedades emergentes do sistema praxiológico, sendo o conceito central das discussões da Praxiologia Motriz. 
et al. (2015) afirmam que o duelo coletivo instiga os jogadores a utilizar de seus melhores recursos e habilidades diante de seus adversários para assim alcançar o objeto comum.

No Voleibol, os jogadores de mesma equipe devem combinar códigos e jogadas entre si para dificultar as ações adversárias, ao mesmo tempo em que devem organizar suas melhores estratégias para pontuar. Além disso, deverão ter o entendimento das funções de cada jogador, facilitando assim o processo de leitura e de transmissão de mensagens a seus companheiros. Para que esse processo ocorra, a equipe deve estar sincronizada, pois para seu bom desempenho perante a equipe adversária será necessário que a mesma realize leituras constantes da conduta motriz ${ }^{8}$ de seus companheiros e também de seus oponentes durante o jogo (RIBAS, 2014). No entanto, os jogadores deverão, a todo o momento, ler e interpretar as mensagens de seus adversários para antecipar-se, concomitantemente deverão transmitir mensagens incertas e duvidosas aos mesmos, com o intuito de dificultar o entendimento de sua conduta motriz. Isso torna-se necessário, porque além de decifrar a conduta de seus oponentes, os mesmos precisam compreender que sua própria conduta é constantemente interpretada, assim, dificultar ao máximo que seus adversários antecipem a sua decisão é imprescindível.

No que diz respeito às formas de manifestações do Voleibol na sociedade, podemos destacar os diferentes caracteres de jogo. Este, por sua vez, é um dos elementos da lógica externa, sendo o cunho atribuído à prática motriz no contexto social na qual ela está inserida, o que consequentemente influencia na maneira como os jogadores realizam suas ações motrizes derivadas da lógica interna. De modo geral, a Praxiologia Motriz, por ser uma ciência que estuda a lógica interna de jogos e esportes, não se dedica a estudar densamente sua lógica externa, porém entende necessário considerá-la em virtude do contexto pedagógico e social de sua intervenção, sendo um elemento que influencia diretamente na manifestação emocional dos jogadores. Podemos citar, além do caráter do jogo, como alguns elementos da lógica externa: o gênero, a idade, o sexo, as características sociais e econômicas, entre outros.

Segundo Parlebas (2001) todas as situações motrizes existentes no campo da Educação Física são compreendidas e agrupadas em quatro grandes subconjuntos, representando a diferença do caráter do jogo. Dessa forma, os quatro subconjuntos são: o Esporte, no qual é o conjunto de situações motrizes em que visa a competição e a institucionalização; os Jogos Esportivos Tradicionais que poderão ser práticas competitivas mas não institucionalizadas internacionalmente; os Exercícios Didáticos, no qual são situações adaptadas, exercícios de preparação e educativos; e por fim as Atividades Livres que são classes não competitivas e sem institucionalização, no qual o praticante atua com maior liberdade (PARLEBAS, 2001).

Com isso, a partir do caráter que o Voleibol assume frente aos objetivos dessa pesquisa, tendo como principal diferença as regras do jogo, podemos destacar o jogo Informal e o jogo Formal, de modo a associá-los aos Jogos Esportivos Tradicionais e ao Esporte,

8 No decorrer da introdução apresentaremos explicações mais aprofundadas acerca da conduta motriz. 
respectivamente, sendo estas as categorias pertencentes às grandes situações motrizes descritas acima. Dessa maneira, decidimos por pesquisar as emoções no Voleibol considerando essas duas formas de manifestação em aulas de Educação Física no contexto escolar.

O ensino do Voleibol na escola vem sendo proposto adotando um caráter Informal e educacional, com suas regras flexíveis, adaptadas e pactuadas pelos alunos conforme suas necessidades. Se constitui muitas vezes em uma prática competitiva, porém não é este seu principal objetivo, aproximando-se portanto das características dos Jogos Esportivos Tradicionais. Para Soares et al. (1992), um dos principais objetivos do esporte escolar é resgatar os valores como a solidariedade e o respeito entre os alunos e entre a sociedade de modo geral, pois o ensinar esporte não pode se resumir apenas em gestos técnicos e a perfeição de movimentos já padronizados. Corroborando com isso, Kunz (2004) afirma que a intenção do esporte pedagógico é tornar o aluno autônomo, crítico e reflexivo em relação às competências objetiva, social e comunicativa. Para isso, em seu processo didático metodológico, é fundamental a transformação didático-pedagógica do esporte na escola, rompendo assim com dois princípios centrais: a comparação objetiva e a sobrepujança.

Por outro lado, a forma como o Voleibol tem sido desenvolvido e tratado no campo social midiático é extremamente voltado ao desempenho e ao rendimento, evidenciando o alcance de melhores resultados. Assim, muitas vezes as características e a intenção desse esporte-performance, são transferidas para o ambiente escolar, fazendo com que o Voleibol assuma um caráter Formal, com regras fixas e institucionalizadas, apresentando como principal objetivo a competição e o resultado final. Portanto, o Voleibol desenvolvido nessas perspectivas vem a ser o Esporte propriamente dito, modulado pela sociedade e pelo sistema capitalista, reproduzindo as competições de alto nível e realizado sobre regras postas pelas instituições internacionais da modalidade.

Em relação à competição, Lavega, March e Filella (2013) afirmam que é possível realizar todas as práticas motrizes com ou sem competição, ou seja, com ou sem vitória final, sendo que quando a mesma evidencia-se os jogadores são classificados em ganhadores e perdedores. Essa competição, quando se faz presente exacerbadamente no contexto escolar, pode refletir positiva ou negativamente acerca do bem-estar sócio emocional dos estudantes (DURAN et al., 2015), podendo contribuir ou não, dependendo das circunstâncias, para o ensino/aprendizagem dos mesmos. Com isso, podemos afirmar que o comportamento emocional dos alunos, além de depender da lógica interna da prática motriz, depende também do caráter do jogo e da dimensão social que essa prática motriz assume diante do contexto no qual ela está inserida.

Além disso, é possível que as emoções suscitadas pelos alunos, decorrentes do caráter do jogo e de sua lógica interna, possam causar alterações no modo como os mesmos irão realizar as ações motrizes provenientes das situações de jogo, influenciando diretamente em sua conduta motriz ${ }^{9}$. A conduta motriz, por sua vez, representa as características internas e

9 A conduta motriz possui três dimensões: cognitiva, relacional e afetiva, no qual todo indivíduo é capaz de desenvolvê-las, sendo que estas variam conforme a prática motriz realizada. Segundo Lavega (2010), a dimensão cognitiva possibilita o praticante avaliar cada situação de jogo para decidir e efetuar suas ações. A 
próprias do participante, no qual cada jogador possui uma maneira única de interpretar e realizar as ações durante o jogo, tendo suas características particulares. Portanto, quando uma ação motriz é realizada por algum jogador, evidenciamos as peculiaridades de quem a realizou, com sua identidade própria, revelando assim sua conduta motriz.

Nos últimos anos, alguns estudos têm sido realizados acerca das emoções, entretanto não foi encontrado até o momento nenhum estudo associado ao Voleibol na manifestação emocional dos alunos no contexto escolar. Com isso, o Voleibol necessita de maiores aprofundamentos científico pelo fato de que ele está sendo intensamente desenvolvido e difundido socialmente, tendo forte presença nos conteúdos escolares. Com base nesses referenciais teóricos até então utilizados, este estudo propõe caracterizar as emoções manifestadas pelos alunos do Colégio Técnico Industrial de Santa Maria em jogos Informais e Formais de Voleibol.

\section{MATERIAL E MÉTODOS}

\section{Desenho do Estudo}

Para alcançar o objetivo desse estudo, optamos por uma metodologia descritiva das emoções considerando aspectos quantitativos e qualitativos. Realizamos um estudo de caráter exploratório, que tem como principal objetivo "desenvolver, esclarecer e modificar conceitos e ideias, tendo em vista a formulação de problemas mais precisos ou hipóteses pesquisáveis para estudos posteriores" (GIL, 2008, p. 27), no qual estabelece a primeira etapa de uma pesquisa mais ampla. Quanto ao tipo de pesquisa, caracterizamos como uma pesquisa de campo, pois coletamos dados junto a participantes, por meio de questionários.

\section{Amostra/população alvo}

Esse trabalho contou com a participação voluntária de 32 estudantes do Colégio Técnico Industrial de Santa Maria (CTISM), da cidade de Santa Maria no Estado do Rio Grande do Sul. Realizamos o estudo com uma turma de $1^{\circ}$ ano do Curso Técnico em Eletrotécnica Integrado ao Ensino Médio, sendo a faixa etária dos alunos de 15 anos. Escolhemos essa turma por questão de acesso, por um dos pesquisadores estar inserido nas aulas como voluntário, auxiliando o professor regente da turma. Além disso, optamos em realizar esse estudo com adolescentes, pelo fato de que a adolescência é uma faixa etária que merece uma maior atenção no que diz respeito à educação emocional dos alunos (ALISTE; ALFARO, 2007), por apresentar características de grande oscilação emocional.

dimensão relacional age na comunicação motriz entre jogadores. Já a dimensão afetiva está associada a todos os sentimentos e emoções envolvidas e desenvolvidas nas situações de jogo. 
Essa pesquisa foi aprovada pelo Comitê de Ética da Universidade Federal de Santa Maria, tendo como número 56232316.5.0000.5346.

\section{Instrumentos}

Para chegarmos aos referidos objetivos aplicamos um questionário com o intuito de identificar as emoções manifestadas pelos alunos em cada partida de Voleibol. A elaboração desse instrumento foi baseada no questionário GES (Games and Emotion Scale) elaborado e validado por Lavega, March e Filella (2013) na Espanha, no qual constitui-se em uma planilha que contêm as trezes emoções organizadas por Bisquerra (2000) e sua intensidade de zero (0) a dez (10).

Assim, o questionário aplicado para a realização da pesquisa também teve como base a organização de Bisquerra (2000), no qual elenca as emoções em positivas (alegria, humor, amor e felicidade), negativas (medo, ansiedade, ira, tristeza, desprezo e vergonha) e ambíguas (surpresa, esperança e compaixão). Diante da exposição aleatória das emoções em uma tabela, o aluno deveria apontar cinco destas que mais foram manifestadas em cada jogo, elencando-as conforme seu grau de relevância, ou seja, da mais para a menos manifestada, e posteriormente responder as questões referentes às emoções listadas.

Gil (2008, p. 121) explicita-nos que o questionário é "um conjunto de questões que são submetidas a pessoas com o propósito de obter informações sobre conhecimentos, crenças, sentimentos, valores [...]". Além disso, Marconi e Lakatos (2003) acrescentam a ideia de que o questionário apresenta vantagens como a liberdade de respostas devido ao anonimato, menor influência do pesquisador sobre as respostas dos sujeitos, no qual possibilita uma avaliação mais uniforme e a obtenção de dados que seriam materialmente inacessíveis.

Aplicamos também o instrumento Histórico Esportivo com o intuito de verificar se os alunos possuíam antecedentes esportivos no Voleibol, pois isso poderia ocasionar alterações em suas emoções durante os jogos. Este questionário foi elaborado pelo GREJE (Grupo de Investigación en Juegos Deportivos y Emociones) do INEFC/Lleida - Espanha, sendo composto por 76 opções de esportes e práticas motrizes referentes ao nosso contexto cultural. Assim, o participante deveria marcar somente uma das opções, desconsiderando as práticas realizadas nas aulas de Educação Física escolar. Se a prática que o mesmo realiza não estivesse contemplada no questionário, havia um local específico para que o participante pudesse apontá-la. Além disso, na parte inferior da folha havia um espaço para o aluno informar sobre a intensidade (anos de experiência e horas semanais) e categoria (nível de prática ou competição) de seu esporte ou prática motriz.

\section{Procedimentos}

Os jogos de Voleibol foram realizados em dois momentos distintos, de forma a representar a diferença do caráter do jogo, sendo primeiramente os jogos Informais 
e posteriormente os Formais. Antes do início do jogo Informal, os alunos definiram e alteraram algumas das regras conforme suas dificuldades e necessidades motoras. Desse modo, estabelecemos as seguintes regras: após o saque, o ataque e/ou o contra-ataque da equipe adversária, era permitido que a bola quicasse até uma vez na quadra antes de algum jogador realizar a recepção ou a defesa; na preparação para o ataque, a equipe poderia efetuar até quatro toques na bola; era permitido, sem grandes exageros, invasão, toque na rede, condução, dois toques e ultrapassar a linha de fundo e dos três metros para executar o saque e o ataque, respectivamente. Contudo, apenas nos jogos Formais foram diferenciados ganhadores de perdedores por meio do questionário aplicado, pois nos jogos Informais não houve contagem dos pontos, visto que o objetivo central deste não era a competição e o resultado.

No início da pesquisa, entregamos uma folha para cada aluno contendo explicações acerca das emoções, para que fosse possível a melhor compreensão do significado de cada uma das emoções no contexto esportivo. Esse material foi retirado e traduzido do artigo de Lavega, March e Filella (2013, p. 155) "Juegos deportivos y emociones. Propiedades psicométricas de la escala GES para ser aplicada en la educación física y el deporte". Posteriormente a leitura, explicação e esclarecimento de dúvidas, em um segundo momento, aplicamos o questionário Histórico Esportivo.

Logo após, os alunos foram divididos aleatoriamente em equipes para o início dos jogos. Assim, tanto no final dos jogos Informais quanto dos Formais, aplicamos o questionário referente às emoções aos alunos que, conforme o término do jogo, iam se retirando da quadra. Exigimos que após a finalização do preenchimento do questionário, os alunos o entregasse imediatamente ao professor responsável pela pesquisa, com o intuito de evitar qualquer manipulação e influência dos dados. Vale ainda destacar que os alunos interviram de forma mista durante os jogos, pois o objetivo da pesquisa não era diferenciar os alunos por sexo para obter relações de gênero.

\section{Variáveis}

A partir dos objetivos dessa pesquisa, foram identificadas as seguintes variáveis: como variável dependente, as emoções positivas, negativas e ambíguas e como variáveis independentes, o caráter do jogo (Informal e Formal) e o resultado da partida (ganhadores e perdedores). Além disso, identificamos como variável controle: a idade, o gênero, a escola e a turma dos participantes. E como variável interveniente: a maturação sexual e a subjetividade das respostas dos questionários.

\section{RESULTADOS E DISCUSSÃO}

A partir do questionário Histórico Esportivo, podemos constatar que dos 32 participantes da pesquisa, apenas um possuía antecedentes esportivos no Voleibol, no qual 
realizava-o de maneira regular e predominante. Além disso, esse aluno realizava essa prática motriz no âmbito do lazer, no qual apresentava pouco tempo de prática e pouca experiência. Assim, podemos afirmar que esse fator, de maneira geral, não ocasionou alterações nos dados da pesquisa, devido a mínima presença de alunos com histórico esportivo no Voleibol.

Por meio do questionário aplicado acerca das emoções e das variáveis independentes da pesquisa, estabelecemos relações entre as emoções, o caráter do jogo e o resultado da partida. Desse modo, apresentamos através de gráficos, as emoções pertencentes às três categorias e suas respectivas frequências de manifestações nos jogos Informais e nos jogos Formais de Voleibol.

\section{Categorias das Emoções e Jogo Informal}

Quando analisamos os dados levando em consideração as categorias das emoções (positivas, negativas e ambíguas) e o caráter do jogo, constatamos que as emoções mais manifestadas e elencadas pelos alunos no jogo Informal foram as positivas (Gráfico 1). Ainda, quando analisadas por participante de maneira individual, com relação às cinco emoções elencadas por cada um deles, verificamos que dos 32 alunos, houve o predomínio de emoções positivas em 16 destes. Além disso, quatro alunos manifestaram mais emoções negativas e em 12 alunos não prevaleceu nenhuma das três categorias devido ao empate ocorrido entre duas delas.

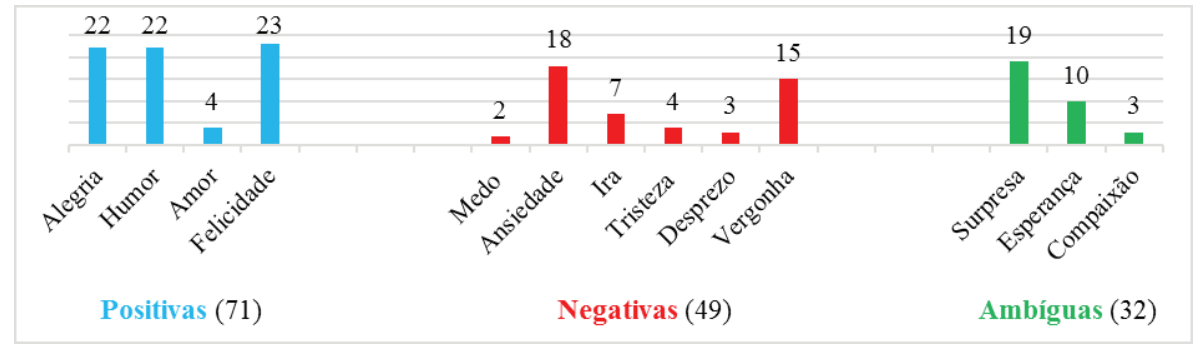

Gráfico 1 - Frequência das Emoções: Jogo Informal

Fonte: Elaborado pelos autores.

Considerando o grau de relevância das emoções, ou seja, as que apresentaram a maior intensidade emocional, as três mais elencadas nos questionários foram o humor, a felicidade e a alegria, sendo emoções positivas. Ainda, quando analisadas de maneira geral, sem levar em consideração a ordem de relevância, a emoção com a maior frequência de manifestação foi a felicidade (Gráfico 1). Além disso, houve outras emoções além das positivas que foram bastante manifestadas, porém obtiveram baixo grau na ordem de hierarquização, como a surpresa e a vergonha. No entanto, houve ainda emoções que além de apresentarem baixo grau de relevância obtiveram baixa frequência de manifestação, como o medo, o desprezo e a compaixão. 
Ao analisarmos as emoções isoladamente por categorias, no grupo das emoções positivas, as mais manifestadas conforme a ordem no grau de relevância foram o humor, a felicidade e a alegria, enquanto analisadas de maneira geral foi a felicidade (como já descrito anteriormente). Ao verificarmos a categoria das emoções negativas, a mais manifestada, tanto em relação à ordem de hierarquização quanto de maneira geral, foi a ansiedade. Já na categoria das ambíguas, conforme a ordem no grau de relevância, as emoções com maior número de manifestações foram a surpresa e a esperança, enquanto de maneira generalizada foi a surpresa.

\section{Categorias das Emoções e Jogo Formal}

A relação estabelecida entre essas duas variáveis foi distinta da anterior, pois quando o caráter que o jogo assume é Formal, com regras institucionalizadas, houve a maior manifestação das emoções negativas, seguida das emoções positivas e por último, e menos manifestadas, as emoções ambíguas (Gráfico 2). Corroborando com esse resultado, quando as emoções são analisadas por participante, constatamos que do total de alunos que responderam o questionário, em sete deles predominaram as emoções positivas, em oito as emoções negativas, em um aluno predominaram as emoções ambíguas e em 16 deles não houve este predomínio por motivo de empate entre duas categorias.

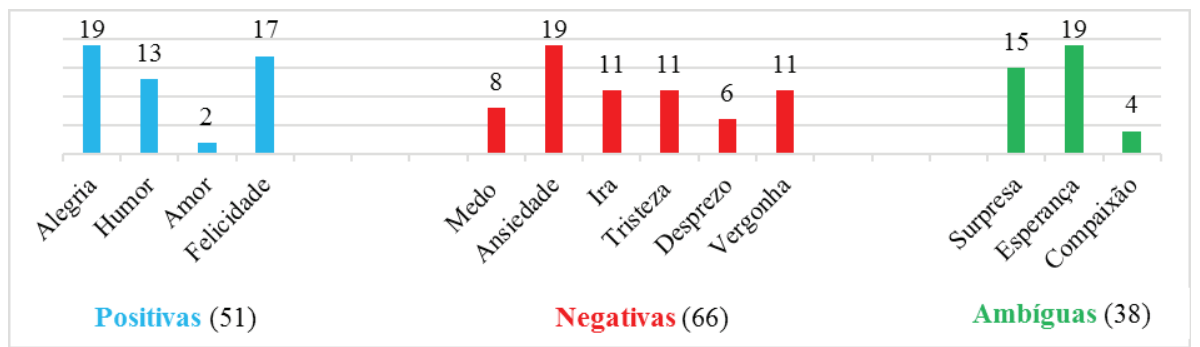

Gráfico 2 - Frequência das Emoções: Jogo Formal.

Fonte: Elaborado pelos autores.

A emoção que obteve maior manifestação conforme a ordem de relevância, na qual apresentou uma grande predominância em relação as demais, foi a ansiedade, sendo portanto uma emoção negativa. Em contrapartida, as emoções mais manifestadas quando analisadas de maneira geral, sem considerar a ordem de hierarquização, foram a ansiedade, a esperança e a alegria (Gráfico 2). Por outro lado, houve também emoções que apresentaram alto índice de manifestação, mas obtiveram baixo grau na ordem de relevância, sendo elas a esperança e a surpresa. No entanto, houve também aquelas que além de apresentarem baixo grau de relevância foram pouco manifestadas pelos alunos, como a compaixão e o desprezo. 
Ao analisarmos as emoções separadamente por categorias, tanto em relação a ordem de hierarquização quanto de maneira geral, a alegria foi a emoção positiva mais manifestada. Na categoria das emoções negativas, a ansiedade foi a emoção mais manifestada, tanto analisada conforme a ordem de relevância quanto de maneira geral. Verificamos também que na categoria das emoções ambíguas, tanto em relação à ordem de hierarquização quanto de maneira geral, a emoção mais manifestada foi a esperança.

Desse modo, ao verificarmos esses dois caracteres de jogo, constatamos que o jogo Informal quando comparado ao Formal, apresentou maior diferença numérica em relação à frequência das emoções positivas e negativas elencadas, sendo 22 vezes mais emoções positivas (Gráfico 1). Essa diferença pode ser evidenciada tanto analisada a partir do total de emoções quanto por participante. Todavia, no jogo Formal essa diferença foi menor, sendo apenas 15 vezes mais emoções negativas (Gráfico 2).

\section{Categorias das Emoções e Jogo Formal - Perdedores}

Quando o jogo Formal é analisado tendo em vista o resultado da partida, constatamos que nos alunos perdedores as emoções negativas obtiveram o valor mais alto no que diz respeito a sua manifestação emocional (Gráfico 3). Além disso, a diferença quantitativa em relação à frequência das emoções positivas e negativas excedeu 30 vezes mais emoções negativas. Isso certamente ocorreu porque além de ser um jogo Formal, os alunos ainda perderam a partida, acarretando em um aumento consideravelmente superior destas emoções.

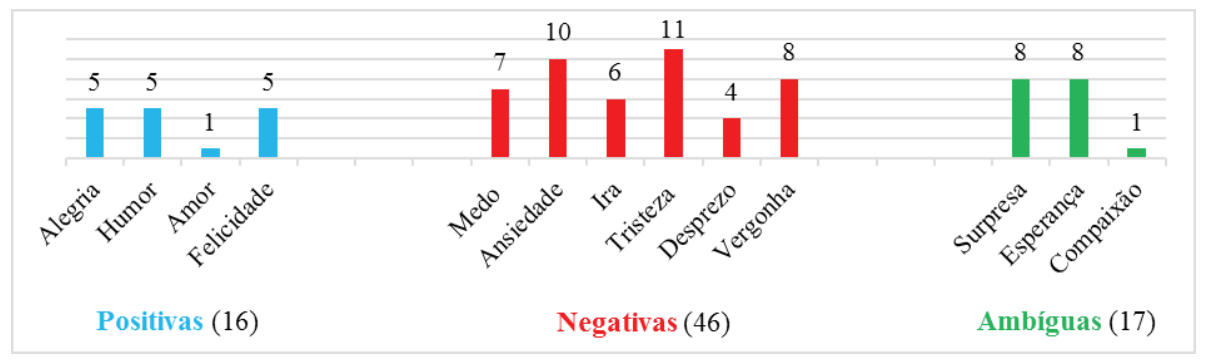

Gráfico 3 - Frequência das Emoções: Jogo Formal - Perdedores.

Fonte: Elaborado pelos autores.

Ao analisarmos os alunos individualmente, dos 16 que perderam o jogo, em dois deles predominaram as emoções positivas, em oito predominaram as emoções negativas, em um as emoções ambíguas e em cinco não houve predomínio. Conforme esse critério, confirmamos a maior manifestação das emoções negativas, também com uma frequência numérica superior. Além disso, as quatro primeiras emoções mais elencadas conforme a intensidade emocional, foram a ansiedade, a ira, a tristeza e a vergonha, respectivamente, 
sendo todas emoções negativas. Ainda, quando analisadas de maneira geral, sem levar em consideração a ordem de relevância, a emoção mais manifestada foi a tristeza (Gráfico 3).

\section{Categorias das Emoções e Jogo Formal - Ganhadores}

Nessa situação em que os alunos foram vencedores do jogo Formal, constatamos que as emoções positivas foram as mais manifestadas, seguida das emoções ambíguas e negativas, respectivamente (Gráfico 4). Ao analisarmos as emoções por participante, verificamos que dos 16 alunos que ganharam o jogo, cinco deles manifestaram mais emoções positivas e em 11 não prevaleceu nenhuma das categorias, se sobressaindo também, conforme esse critério de análise, as emoções positivas. No entanto, a emoção mais elencada pelos alunos vencedores conforme a ordem de relevância foi uma emoção negativa, sendo ela a ansiedade, e em sucessão foi a alegria. Todavia, sem levar em consideração a ordem de hierarquização, a emoção com o maior número de manifestação foi a alegria (Gráfico 4).

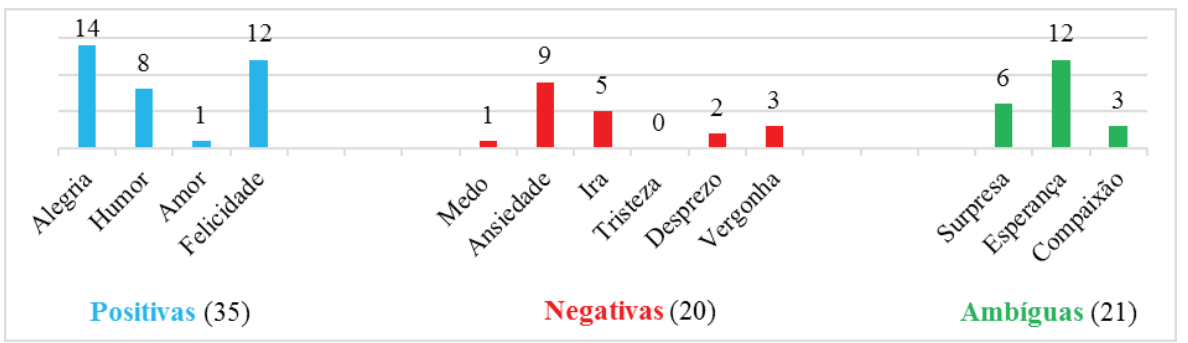

Gráfico 4 - Frequência das Emoções: Jogo Formal - Ganhadores.

Fonte: Elaborado pelos autores.

Ao analisarmos o gráfico acima, verificamos que a diferença numérica em relação à frequência das emoções positivas e negativas elencadas foi menor quando comparada à situação anterior, sendo ela de apenas 15, excedendo emoções positivas. Assim, mesmo apresentando um valor mais elevado de emoções positivas pelo fato dos alunos terem vencido o jogo, o caráter do mesmo era Formal, o que suscitou também em emoções negativas, acarretando, portanto em um maior equilíbrio quantitativo. Além disso, continua sendo uma emoção negativa a de maior ordem de relevância, ratificando o caráter Formal do jogo.

Para o autor Lagardera (1999), a competição esportiva ocasiona uma polaridade afetiva e emocional, por um lado proveniente do medo de perder e por outro lado derivada da expectativa de ganhar. Assim, todas as emoções podem manifestar-se com diferentes valores de intensidade, dependendo de suas variáveis correspondentes. Contemplando essa ideia, Lavega, March e Filella (2013), em sua investigação acerca das três categorias das emoções, constataram que as emoções negativas e as ambíguas obtiveram valores mais elevados de intensidade em práticas pertencentes ao domínio de cooperação e oposição, categoria a qual está situado o Voleibol. 
Dentre outros estudos acerca das emoções manifestadas por alunos em aulas de Educação Física, destacamos uma pesquisa realizada por Duran et al. (2015) que teve como público alvo adolescentes. Nessa investigação, os autores utilizaram de práticas motrizes pertencentes aos quatro domínios de ação motriz (psicomotriz, sociomotriz de oposição, sociomotriz de cooperação e sociomotriz de cooperação e oposição), em jogos competitivos e em jogos não competitivos. A partir dos resultados desse estudo, os autores concluíram que nos jogos não competitivos e pertencentes ao domínio sociomotriz de cooperação e oposição, a alegria e o humor apresentaram alta intensidade emocional, sendo que nesses jogos não se comparou nem se classificou os alunos em ganhadores e perdedores. Desse modo, podemos perceber que no estudo em questão, a maior intensidade de emoções positivas manifestou-se em jogos do domínio sociomotriz, no qual o Voleibol é pertencente, e principalmente naqueles em que o resultado não foi considerado.

Por outro lado, Duran et al. (2015) constataram que a presença da competição nas práticas motrizes foi a principal responsável pela manifestação e pela alta intensidade das emoções negativas. Através dos resultados de nosso estudo, também certificamos que a competição tende a aumentar a manifestação de emoções negativas, principalmente em alunos que não obtém os melhores resultados. Portanto, é de extrema importância que o professor de Educação Física, ao programar os conteúdos, leve em consideração essas questões relacionadas aos domínios da ação motriz e principalmente a relação da competição esportiva e a classificação dos alunos em ganhadores e perdedores.

Além dos dados dispostos em gráficos até então apresentados e discutidos, estabelecemos relações a partir das respostas descritivas que apresentaram maior predominância nos questionários. Assim, em relação à conduta motriz, podemos afirmar que houve grande influência das emoções no modo particular de cada jogador realizar as ações motrizes durante o jogo. Lavega (2011, p. 26) explicita-nos que "quando os jogadores participam em qualquer jogo, suas condutas motrizes estão impregnadas de emoções, se trata de vivências carregadas de uma clara efervescência emocional". Desse modo, tanto no jogo Informal quanto no Formal, destacamos, de acordo com as respostas obtidas nos questionários, que a partir das emoções positivas até então manifestadas, os alunos demonstraram maior motivação, interesse e esforço para realizar as ações motrizes no decorrer do jogo, atribuindo a estas emoções o aumento do percentual de acertos. Já em relação às emoções negativas, as mesmas ocasionaram a falta de atenção, concentração e esforço dos alunos, o que na maioria das vezes foi expresso através de erros em determinadas situações do jogo.

Quando questionados sobre a influência que seus companheiros de equipe tiveram sobre suas emoções, a maioria dos jogadores destacou que tanto no jogo Informal quanto no Formal, seus companheiros contribuíram para a manifestação de emoções positivas quando colaboraram e cooperaram com os demais membros da equipe, bem como quando acertavam determinadas ações e assim pontuavam. Já para as emoções negativas, os companheiros tiveram influência quando não realizavam corretamente suas ações durante o jogo e quando julgavam os demais pelos erros cometidos, o que causou em alguns momentos o desentendimento entre eles. Desse modo, podemos constatar que as emoções negativas não resultam apenas das relações estabelecidas entre adversários, através da interação de 
oposição, mas também entre os próprios companheiros de equipe, principalmente em situações de erros, causando consequentemente discussão e desentendimento.

De maneira geral, a maior diferença que repercutiu entre o caráter do jogo na grande maioria das respostas, foi que quando o jogo era Informal elas estavam relacionadas a fatores e ações oriundas da partida, como por exemplo, a cooperação e o apoio existente entre companheiros, a pontuação, os acertos e os erros. Todavia, quando o jogo assumia o caráter Formal, a maioria das respostas remeteu-se à vitória e à derrota, ou seja, estava associada ao resultado final da partida, tanto analisado a partir de companheiros quanto de adversários.

No que diz respeito somente ao jogo Formal, dos 32 alunos participantes da pesquisa, 25 deles responderam que o resultado final da partida influenciou na manifestação de suas emoções. Assim, para aqueles que perderam o jogo, o resultado propiciou na manifestação predominantemente da tristeza e da ira, na qual são emoções negativas. Por outro lado, para os vencedores, o resultado estimulou a excitação de algumas emoções positivas, sendo elas principalmente a felicidade e a alegria.

Desse modo, podemos afirmar que o fato do aluno ter vencido o jogo não o faz manifestar mais emoções positivas, mas sim o caráter que o jogo assume, pois quando o mesmo era Formal a frequência das emoções negativas manifestadas foi superior em relação às demais emoções (Gráfico 2). Essa afirmação é comprovada ao verificarmos que a ansiedade apresentou maior intensidade emocional em todas as situações em que o jogo era Formal, tanto sendo analisado de maneira geral, quanto especificamente, na condição de perdedores e até mesmo de ganhadores. No entanto, somente quando o caráter do jogo era Informal, as emoções positivas obtiveram a maior frequência de manifestação (humor, felicidade e alegria). Isso corrobora com a premissa de que as emoções positivas não se sobressaem somente diante da conquista de melhores resultados competitivos, mas sim quando não há a classificação de ganhadores e perdedores e principalmente quando as regras do jogo são flexíveis e levam em consideração as dificuldades dos alunos, as características de sua faixa etária e seu momento educativo. Na tabela a seguir, apresentamos uma síntese com os principais resultados obtidos no estudo considerando as características e objetivos do jogo Informal e Formal.

No final da década de 80, a Educação Física brasileira retratou um importante cenário acadêmico de debate que passava pela concepção de Educação Física em direção às novas propostas pedagógicas da área. Estas propostas apresentaram relevantes reflexões sobre o esporte da escola que superava os modelos esportivos institucionalizados, contemplando o aspecto educacional. Em suma, os principais pontos questionados por essas teorias pedagógicas foram: especialização precoce; regras definidas pelas instituições esportivas que não eram adaptadas ao contexto escolar; competição e alto rendimento como elementos centrais do ensino dos esportes; ausência de reflexão sobre o contexto esportivo e suas relações com o contexto social, principalmente o vínculo dos princípios do esporte de alto rendimento com o sistema capitalista; dentre outros temas sociais relativos ao esporte. 
Tabela 1 - Apontamentos Centrais e Principais Resultados da Pesquisa.

\begin{tabular}{|c|c|c|c|}
\hline $\begin{array}{l}\text { Apontamentos } \\
\text { e Resultados }\end{array}$ & Jogo Informal & \multicolumn{2}{|c|}{ Jogo Formal } \\
\hline $\begin{array}{l}\text { Principais } \\
\text { Características }\end{array}$ & $\begin{array}{l}\rightarrow \text { Jogo Esportivo } \\
\text { Tradicional } \\
\rightarrow \text { Regras flexíveis e } \\
\text { adaptadas ao contexto } \\
\rightarrow \text { Instrumento } \\
\text { Educacional } \\
\rightarrow \text { Vínculo com a } \\
\text { cultura/comunidade } \\
\text { local }\end{array}$ & \multicolumn{2}{|c|}{$\begin{array}{l}\rightarrow \text { Esporte } \\
\rightarrow \text { Regras fixas e institucionalizadas } \\
\rightarrow \text { Subordinação ao órgão oficial responsável } \\
\rightarrow \text { Vínculo com o sistema Capitalista }\end{array}$} \\
\hline Objetivos & $\begin{array}{l}\rightarrow \text { Aprendizagem e } \\
\text { participação dos alunos, } \\
\text { (definição de formas, } \\
\text { regras e do próprio jogo) } \\
\rightarrow \text { Inclusão de todos } \\
\rightarrow \text { Formação de um } \\
\text { aluno crítico e autônomo }\end{array}$ & \multicolumn{2}{|c|}{$\begin{array}{l}\rightarrow \text { Competição } \\
\rightarrow \text { Valorização do resultado final } \\
\text { (ganhadores/perdedores) } \\
\rightarrow \text { Valorização da performance }\end{array}$} \\
\hline & $\begin{array}{l}\text { Predominância de } \\
\text { Emoções Positivas } \\
\rightarrow \text { Humor, Felicidade e }\end{array}$ & \multicolumn{2}{|c|}{$\begin{array}{l}\text { Predominância de Emoções Negativas } \\
\rightarrow \text { Ansiedade (intensidade) } \\
\rightarrow \text { Ansiedade, Esperança, Alegria (geral) }\end{array}$} \\
\hline $\begin{array}{l}\text { Resultados } \\
\text { Quantitativos }\end{array}$ & $\begin{array}{l}\text { Alegria (1ntensidade) } \\
\rightarrow \text { Felicidade (geral) }\end{array}$ & $\begin{array}{l}\quad \text { Perdedores } \\
\text { Predominância de } \\
\text { Emoções Negativas } \\
\rightarrow \text { Ansiedade, Ira, } \\
\text { Tristeza e Vergonha } \\
\text { (intensidade) } \\
\rightarrow \text { Tristeza (geral) }\end{array}$ & $\begin{array}{l}\text { Ganhadores } \\
\text { Predominância de } \\
\text { Emocões Positivas } \\
\rightarrow \text { Ansiedadee } \\
\text { Alegria } \\
\quad \text { (intensidade) } \\
\rightarrow \text { Alegria (geral) }\end{array}$ \\
\hline $\begin{array}{l}\text { Respostas } \\
\text { Descritivas }\end{array}$ & $\begin{array}{l}\rightarrow \text { Fatores decorrentes } \\
\text { do jogo (pontuação, } \\
\text { acertos, erros...) }\end{array}$ & \multicolumn{2}{|c|}{$\begin{array}{l}\rightarrow \text { Fatores decorrentes da Competição e do } \\
\text { Resultado do jogo (vitória e derrota) }\end{array}$} \\
\hline
\end{tabular}

Fonte: Elaborada pelos autores.

Esses temas foram tratados de forma mais específica no final da década de 90 através do debate "Esporte na Escola e Esporte da Escola". A temática sugeria apontar para o esporte que, ao ser tematizado na escola, deveria atender as seguintes questões: adequação ao contexto escolar para que os alunos tivessem acesso a este conhecimento considerando as novas concepções pedagógicas da Educação Física; necessidade de reflexão desta manifestação cultural como prática social; ruptura do caráter institucionalizado, tornando as regras mais flexíveis, inclusivas e pactuadas pelos alunos, descentralizando o caráter competitivo. O debate se deu principalmente na revista Movimento em uma seção denominada "temas polêmicos" com importantes autores da área como: Adroaldo Gaya, Elenor Kunz, Hugo Lovisolo, Marco Paulo Stigger, Tarciso Mauro Vago e Valter Bracht. 
Em relação à competição inserida no ambiente escolar, dependendo da forma como é imposta aos alunos, esta pode ser excludente se estiver voltada ao desempenho esportivo, pois poucos são beneficiados ao categorizá-los em ganhadores/perdedores. Além disso, ao estar presente nas aulas de Educação Física de maneira exacerbada, a competição diminui a autoestima dos alunos e aumenta o medo de errar, influenciando em seu desenvolvimento (MAIA; MAIA; MARQUES, 2007). Corroborando com essa ideia, Brotto (1999) afirma que o jogo competitivo na escola, através de algumas situações, é capaz de abolir sentimentos prazerosos como o divertimento e a alegria advindas da prática, além de excluir os alunos menos habilidosos. Mais recentemente, Bracht (2009) esclarece que o esporte desenvolvido no ambiente escolar como um dos conteúdos da Educação Física não deve conceder como significado central o rendimento máximo e a competição, devendo ter um outro sentido diferente daquele presente no esporte de alto nível.

Darido et al. (1999), certificaram que quando as aulas de Educação Física visam a competição esportiva e a valorização da vitória, os alunos acabam se afastando dessa disciplina escolar, por privilegiar os mais hábeis e os que apresentam maiores facilidades motoras, principalmente se tratando do ensino médio. Dessa forma, quando o resultado torna-se o objetivo central da prática, o esporte perde sua essência da diversão, do bem-estar e de sua aprendizagem como conteúdo escolar (MUNIZ; BORGES, 2013). Além disso, isso sucede pela imposição de suas regras, pois muitas vezes elas são apenas transferidas do esporte institucionalizado para a escola, com pouquíssimas alterações e adaptações (FERREIRA, 2000), princípios estes característicos do "esporte na escola".

Contudo, para Frajácomo et al. (2007), um dos principais objetivos da Educação Física escolar é desenvolver seus conteúdos de forma a adaptá-los para que não haja diferenciação de habilidades e tão pouco a exclusão de alunos, com o intuito de tornar sua prática acessível a todos. Desse modo, é preciso que os professores compreendam e trabalhem o esporte no contexto escolar atribuindo-Ihe um viés educacional e estabelecendo regras flexíveis que visem a aprendizagem dos alunos. Assim, os pesquisadores da área indicam a necessidade da transformação didático-pedagógica do esporte que supere o modelo institucionalizado, refletindo sobre a concepção de esporte prevista para o alto rendimento e considerando-o como uma manifestação cultural produzida pelo e para o ser humano.

\section{CONCLUSÕES}

A partir dos resultados da pesquisa, constatamos que o Voleibol propicia e estimula em seus participantes, por meio de sua prática, a excitação de diferentes emoções, sendo elas positivas, negativas e ambíguas. Assim, a manifestação dessas emoções depende principalmente das variáveis independentes: caráter do jogo e resultado da partida.

Em relação ao caráter do jogo, as emoções positivas obtiveram a maior frequência de manifestação quando o caráter do jogo era Informal, enquanto nos jogos Formais as emoções que prevaleceram foram as negativas. No entanto, em relação ao resultado da partida, a manifestação de emoções positivas predominou em alunos que venceram o jogo, 
enquanto que as emoções negativas obtiveram a maior frequência de manifestação em alunos que foram perdedores. As emoções ambíguas, por sua vez, não foram predominantes em nenhuma situação de jogo, porém apresentaram uma frequência de manifestação considerável quando comparada as demais emoções.

Com isso, constatamos que o esporte em si não implica no prestígio de alguns alunos e na exclusão de outros. No entanto, o que pode torná-lo assim é a forma como o mesmo é proposto, ou seja, quando seu objetivo central é o resultado e a competição, sem um processo de transformação didático-pedagógica do esporte na escola para o esporte da escola, sendo estas características as principais responsáveis pela manifestação de emoções negativas. Dessa forma, o professor deve desenvolver os conteúdos escolares identificando principalmente as questões pedagógicas, as individualidades dos alunos e sua conduta motriz, levando em consideração seu caráter pedagógico que está contemplado na proposta da Educação Física. Entendemos ainda que esses conteúdos devem oportunizar a manifestação das mais variadas emoções para que os alunos possam vivenciá-las e compreende-las, proporcionando assim, uma ampla experiência emocional.

Desse modo, não queremos aqui negar ou abolir a competição e tão pouco o esporte no contexto escolar, mas sim tratar a competição pedagogicamente com ênfase na educação do aluno, reduzindo a exclusão e os níveis de violência, visando a maior participação e o aprendizado de todos, de modo a contrastar e refletir em relação ao esporte de alto rendimento como modelo social. A exemplo dessa pesquisa realizada no Voleibol, compreendemos que o ensino na Educação Física poderá viabilizar um ensino mais significativo e qualificado, considerando os distintos âmbitos das emoções que os jogos Informais e Formais despertam. Evidentemente que estes resultados deverão ser reinterpretados de acordo com a concepção pedagógica do professor, ou seja, cada concepção tratará as questões constatadas nesse estudo de acordo com seus princípios pedagógicos e didáticos.

\section{REFERÊNCIAS}

ALISTE, Aurora; ALFARO, Vivianne. Educación emocional una alternativa para evitar el fracaso escolar y social. Educación, v. 3, n. 4, p. 81-95, 2007.

BISQUERRA, Rafael. Educación emocional y bienestar. Barcelona: Praxis, 2000.

BISQUERRA, Rafael. Educación emocional y competencias básicas para la vida. Revista de Investigación Educativa, v. 21, n. 1, p. 7-43, 2003.

BRACHT, Valter. Esporte de rendimento na escola. In: STIGGER, Marco Paulo; LOVISOLO, Hugo (Orgs.). Esporte de rendimento e esporte na escola. Campinas, SP: Autores Associados, 2009, p. 11-26.

BROTTO, Fábio Otuzi. Jogos cooperativos: o jogo e o esporte como um exercício de convivência. 1999. 209 f. Dissertação (Mestrado em Educação Física) - Universidade Estadual de Campinas, Campinas, 1999.

DARIDO, Suraya Cristina et al. Educação Física no ensino médio: reflexões e ações. Motriz, Rio Claro, v. 5, n. 2, p. 138-145, dez. 1999. 
DURAN, Conxita et al. Educación física emocional en adolescentes. Identificación de variables predictivas de la vivencia emocional. Cultura, Ciencia y Deporte (CCD), v. 10, n. 28, p. 5-18, 2015.

FAGUNDES, Felipe Menezes; OLIVEIRA, Raquel Valente de; RIBAS, João Francisco Magno. Saque e Recepção: análises praxiológicas sobre suas influências no Voleibol. In: CONGRESO ARGENTINO Y LATINOAMERICANO DE EDUCACIÓN FÍSICA Y CIENCIAS, 11.; 6., La Plata, 2015. Anais eletrônicos... La Plata: Facultad de Humanidades y Ciencias de la Educación de la Universidad Nacional de La Plata, 2015. p. 1-16. Disponível em: < http://congresoeducacionfisica.fahce.unlp.edu.ar/ publicaciones-11 ocongreso/Mesa\%2004_Fagundes.pdf/view? searchterm $=$ None $>$. Acesso em: 04 abr. 2016.

FERREIRA, Marcos Santos. Ponto de vista. A competição na educação física escolar. Motriz, Rio Claro, v. 6, n. 2, p. 97-100, jul./dez. 2000.

FRAJÁCOMO, Mauricio Tadeu et al. "Adaptações de modalidades esportivas" propostas de atividades para a educação física no ensino fundamental. Revista Uniara, Araraquara, n. 20, p. 167-176, 2007.

GIL, Antônio Carlos. Métodos e técnicas de pesquisa social. 6 ed. São Paulo: Atlas, 2008. GOLEMAN, Daniel. Inteligência emocional. Rio de Janeiro: Objetiva, 1996.

KUNZ, Elenor. Transformação didático-pedagógica do esporte. 6. ed. Ijuí: Unijuí, 2004. LAGARDERA, Francisco. La lógica deportiva y las emociones. Implicaciones en la enseñanza del deporte. Revista Apunts de Educación Física, n. 56, p. 99-107, 1999.

LAGARDERA, Francisco; LAVEGA, Pere. Introducción a la praxiología motriz. Barcelona: Paidotribo, 2003.

LAVEGA, Pere. Dominios de acción motriz y afectividad. In: SEMINARIO INTERNACIONAL Y LATINOAMERICANO DE PRAXIOLOGÍA MOTRIZ: EDUCACIÓN FÍSICA Y CONTEXTOS CRÍTICOS, 14.; 2., La Plata, 2011. Anais eletrônicos... La Plata: Facultad de Humanidades y Ciencias de la Educación de la Universidad Nacional de La Plata, 2011. p. 1-36. Disponível em: < http://www.memoria.fahce.unlp.edu.ar/ trab_eventos/ev.1413/ev.1413.pdf>. Acesso em: 20 abr. 2016.

LAVEGA, Pere. Juegos tradicionales, emociones y educación de competencias. In: CURSO DE FORMACIÓN SOBRE O PATRIMONIO LÚDICO. O JOGO TRADICIONAL E AS DIDÁCTICAS ESPECIFICAS, 2., Melide, 2010. Anais eletrônico... Melide: Consellería de Educación e Ordenación Universitaria, 2010. p. 1-12. Disponível em: < http:// www.nova-escola-galega.org/almacen/documentos/Texto \%20Pere \% 20Lavega- \% 20 Melide\%202010.pdf > . Acesso em: 24 nov. 2015.

LAVEGA, Pere. Praxiología motriz y Educación Física. Acción motriz, n. 4, p. 3-4, 2010. LAVEGA, Pere; ARÁUJO, Paulo; JAQUEIRA, Ana Rosa. Enseñar competencias motrices y emocionales en estudiantes universitarios. Cultura, Ciencia y Deporte (CCD), v. 8, n. 22, p. 5-15, 2013.

LAVEGA, Pere; MARCH, Jaume; FILELLA, Gemma. Juegos deportivos y emociones. Propiedades psicométricas de la escala GES para ser aplicada en la educación física y el deporte. Revista de Investigación Educativa, v. 31, n. 1, p. 151-166, 2013. 
LAVEGA, Pere et al. Efecto de la cooperación motriz en la vivencia emocional positiva: perspectiva de género. Revista Movimento, v. 20, n. 2, p. 593-618, 2014.

MAIA, Raquel Ferreira; MAIA, Jusselma Ferreira; MARQUES, Maria Teresa da Silva Pinto. Jogos cooperativos $x$ jogos competitivos: um desafio entre o ideal e o real. Revista Brasileira de Educação Física, Esporte, Lazer e Dança, Santo André, v. 2, n. 4, p. 125-139, dez. 2007.

MARCONI, Marina de Andrade; LAKATOS, Eva Maria. Fundamentos de metodologia científica. 5 ed. São Paulo: Atlas, 2003.

MUNIZ, Igor Barbarioli; BORGES, Carlos Nazareno Ferreira. Jogos cooperativos, jogos competitivos e a classificação subjetiva. Impulso, Piracicaba, v. 23, n. 58, p. 103-114, 2013.

PARLEBAS, Pierre. Juegos, deporte y sociedad. Léxico de Praxiología Motriz. Barcelona: Paidotribo, 2001.

RIBAS, João Francisco Magno (Org.). Praxiologia motriz e voleibol: elementos para o trabalho pedagógico. ljuí: Unijuí, 2014.

SOARES, Carmen Lúcia et al. Metodologia do ensino de educação física. São Paulo: Cortez, 1992.

Recebido em: setembro/2016 Aprovado em: janeiro/2017 